\section{Einladung zur Landesversammlung des}

\section{FVDZ Rheinland-Pfalz}

Termin: Samstag, 13. Mai 2017

Beginn: 09.30 Uhr

Ort: $\quad$ Novotel Mainz

Augustusstr. 6

55131 Mainz

Sehr geehrte Frau Kollegin, sehr geehrter Herr Kollege, hiermit laden wir Sie ein zur Landesversammlung Rheinland-Pfalz.

\section{Tagesordnung:}

1. Eröffnung durch den Versammlungsleiter

2. Begrüßung durch die Landesvorsitzende

3. Grußworte

4. Bericht der Landesvorsitzenden (anschließend Ehrungen langjähriger Mitglieder)

5. Vortrag mit anschließender Diskussion:

Kernthema Bürgerversicherung im Wahljahr 2017

Analyse einer "gesundheitspolitischen Schöpfung“

Referent: Rechtsanwalt Michael Lennartz;

Justiziar des Freien Verbandes Deutscher Zahnärzte e.V., Lehrbeauftragter LL.M.-Studiengang Medizinrecht, Universität Düsseldorf

\section{Ende der öffentlichen Sitzung/Mittagspause}

Der Landesvorstand Rheinland-Pfalz lädt hiermit gemäß $\$ 14$ Abs. 2-6 der Satzung seine stimmberechtigten Mitglieder zur Landesversammlung 2017 ein; ebenso sind alle Kolleginnen und Kollegen aus Rheinland-Pfalz zum öffentlichen Teil der Veranstaltung gern gesehene Gäste. Anträge sind bis spätestens zwei Wochen vor der Landesversammlung über die Landesgeschäftsstelle schriftlich einzureichen und zu begründen.

Mit freundlichen kollegialen Grüßen

Dr. Ulrike Stern, Vorsitzende

Dr. Christian Honert, stellv. Vorsitzender Dr. Boris Brehmer, stellv. Vorsitzender

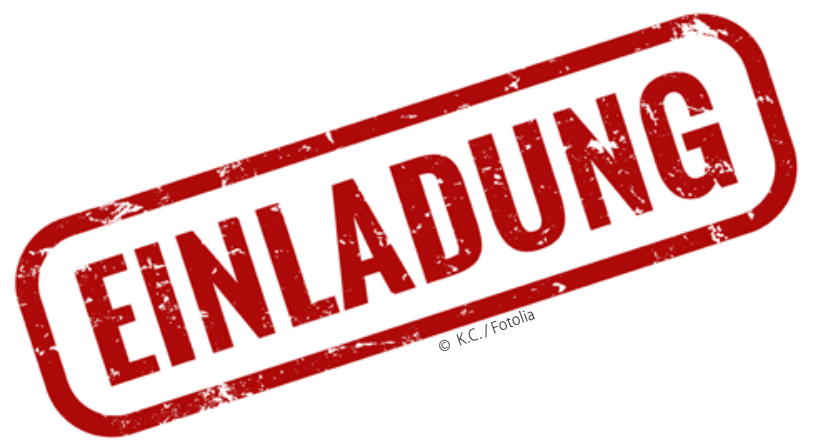

\section{Einladung zur Landesversammlung des}

\section{FVDZ Nordrhein}

Termin: Mittwoch, 17. Mai 2017

Beginn: $14.30 \mathrm{Uhr}$

Ort: Zahnärztekammer Nordrhein

Emanuel-Leutze-Str. 8

40547 Düsseldorf

Sehr geehrte Frau Kollegin, sehr geehrter Herr Kollege, gemäß $\$ 14$ Abs. 2 der Satzung laden wir hiermit alle Mitglieder des Freien Verbandes Deutscher Zahnärzte e.V. in Nordrhein ganz herzlich ein.

\section{Tagesordnung:}

1. Eröffnung und Begrüßung durch den Landesvorsitzenden

2. Regularien

3. Fragestunde

Die Fragen müssen schriftlich mindestens fünf Tage vor der Landesversammlung in der Landesgeschäftsstelle eingegangen sein. Die Fragen dürfen sich nicht auf Punkte der Tagesordnung beziehen.

4. Referat: „Mehr Freiheit im Gesundheitswesen statt noch mehr Staatsmedizin“"

Referent: Dr. Heiner Garg (MdL)

Landesvorsitzender der FDP in Schleswig Holstein

Parlamentarischer Geschäftsführer der FDP-Landtagsfraktion $\mathrm{SH}$

5. Bericht des Landesvorsitzenden

6. Bericht der Kassenprüfer über das Jahr 2016

7. Jahresrechnung 2016

8. Entlastung des Vorstandes

9. Wahlen für den Landesvorstand:

9.1 Wahl des Landesvorsitzenden

9.2. Wahl von zwei Stellvertretern

9.3. Wahl von fünf Beisitzern

10. Wahl von zwei Delegierten und Ersatzdelegierten zur Hauptversammlung (Überhangmandate)

11. Wahl von zwei Kassenprüfern und deren Stellvertreter

12. Haushaltsplan für das Jahr 2017

13. Anträge

Anträge, die die Tagesordnung verändern, sind spätestens zwei Wochen vor der Landesversammlung beim Landesvorstand über die Landesgeschäftsstelle einzureichen. Die Anträge sind zu begründen.

14. Verschiedenes

Die Landesversammlung ist für Mitglieder des Freien Verbandes öffentlich. Rede- und stimmberechtigt sind nur die Delegierten.

Mit freundlichen kollegialen Grüßen

Ihr

Dr. Thorsten Flägel, Vorsitzender 